\title{
On the convergence of the Generalized ibn Ezra Value
}

\author{
Louis de Mesnard
}

Univ. Bourgogne Franche-Comté, CREGO (EA 7317).

IAE Dijon, 2 Bd Gabriel, 21000 DIJON, FRANCE.

E-mail: louis.de-mesnard@u-bourgogne.fr

\begin{abstract}
Ibn Ezra (ibn Ezra 1146; Rabinovitch 1973; O’Neill 1982) proposed a method for solving the "rights arbitration problem" (one of the historical problems of "bankruptcy") for n claimants when the estate $\mathrm{E}$ is equal to the largest claim. However, when the greatest claim is for less than the estate, the question of what to do with the difference between $E$ and the largest claim is posed. Alcalde et al.'s (2005) Generalized ibn Ezra Value (GiEV), solves the problem in $\mathrm{T}$ iterations, of $\mathrm{n}$ steps.

By using Monte-Carlo experiments, we show that: (i) T grows linearly with the number of claimants, which makes GiEV rapidly impracticable for real applications. (ii) The more $\mathrm{E}$ is close to the total claim $\mathrm{d}$, the more $\mathrm{T}$ grows: $\mathrm{T}$ linearly grows when $\mathrm{E}$ exponentially approaches $\mathrm{d}$ by a factor 10. Moreover, we proved through theory that GiEV fails to provide a solution in a finite number of iterations for the trivial case $\mathrm{E}=\mathrm{d}$, whereas it should obviously find a solution in one iteration. So, even if GiEV is convergent, the sum of claims $d$ appears as an asymptote: the number of iterations tends to infinite when the estate $\mathrm{E}$ approaches the claims total d. We conclude that GiEV is inefficient and usable only when: (1) the number of claimants is low, and (2) the estate $\mathrm{E}$ is largely lower than the total claims d.
\end{abstract}

JEL classification. D31, D63, D71, B1, B4

Keywords. Game theory; ibn Ezra; bankruptcy; rights arbitration; cooperative game; convergence; Monte-Carlo experiments.

Running head. Convergence of the Generalized ibn Ezra Value. 


\section{Introduction}

In an allocation problem, when the estate to be shared $E$ is larger than the sum of claims $d$, each claimant is obviously served without any rationing. The allocation problem, the so-called "bankruptcy problem", begins when the value of the estate amounts to less than the sum of the claims. When the estate to be shared $E$ is just equal to the sum of the claims $d$, i.e., $E=d$, the whole estate can be allocated without any competition between the claimants, each one trivially receiving exactly what he claims. Ibn Ezra (ibn Ezra 1146; Rabinovitch 1973; O'Neill 1982; Bergantiños and Méndez-Naya 2001; Chun and Thomson 2005; Alcalde et al. 2008) proposed a method for solving the bankruptcy problem that he called the rights arbitration problem ${ }^{1}$ where the estate $E$ is equal to the greatest claim of $n$ claimants. As expounded by O'Neill (1982), it can be solved in $n$ steps and poses no difficulty. However, when the maximum claim is for less than the available estate, the question is: what do we do with the difference between the estate and the largest claim? Who receives it? A number of solutions are possible. The most popular is O'Neill's (1982) Minimal Overlap Rule. ${ }^{2}$ Alcade et al. (2005) criticize this procedure because it mixes two principles of equity: "Up to a certain amount of estate we should follow the recommendations by Ibn Ezra and, after it, we should divide divide the extra estate trying to equalize agents' loses" (Alcalde et al. 2005, p. 15). ${ }^{3}$ This is why they propose another attractive solution, the Generalized ibn Ezra Value, by imposing "that the general principle in which the recommendations by this author [ibn Ezra] are inspired should remain fixed" (Alcalde et al. 2005, p. 15). This method is iterative, that is, we have $T$ iterations (each one including the $n$ steps of ibn Ezra - O'Neill). In this paper, we examine the computational and mathematical properties of the algorithm of the Generalized ibn Ezra Value to explain why the method poses problems.

\section{Ibn Ezra's problem in formalized terms}

A bankruptcy problem is defined as follows. Consider a finite set $N=\{1, \ldots, n\}$ of claimants or creditors (with $|N|=n$ ), a vector $\mathbf{d} \in \mathbb{R}^{n}$ of claims ordered in increasing order, i.e., $d_{1} \leq d_{2} \leq \ldots \leq d_{n}$; we denote $d \equiv \sum_{i=1}^{n} d_{i}$ and consider an estate to be distributed $E \in \mathbb{R}_{+}$. The resource is scarce: $E \leq d$. The solution is the payoff vector $\mathbf{x} \in \mathbb{R}^{n}$. By denoting $x \equiv \sum_{i=1}^{n} x_{i}$, the solution is such that the following axioms are fulfilled: ${ }^{4}$

1. Axiom 1. $0 \leq x_{i} \leq d_{i}$ for any $i \in N$ : no one can receive more than he claims.

\footnotetext{
${ }^{1}$ It is one of the historical problems of "bankruptcy", posed years ago.

${ }^{2}$ See also Chun and Thomson (2005) or Alcalde et al. (2008). The Minimal Overlap Rule is also called Minimal Overlap Value.

${ }^{3}$ This second rule is the so-called Constrained Equal Loss Rule.

${ }^{4}$ For more about the axiomatic approach to bankruptcy problems, see Peyton Young (1987) or Thomson (2003).
} 


\section{Axiom 2. $x=E$.}

We suppose that $d \geq E$, where $d \equiv \sum_{i=1}^{n} d_{i}$, that is, the problem is a "rationing" problem. For $E>d$, the problem is trivial: it is no longer a bankruptcy game because each claimant receives what he/she claims.

Remark. For $E=d$, any allocation problems turn out to be trivial: they turn into a simple division, with each claimant receiving exactly what he claims, that is, $x_{i}=d_{i}$ for any $i$ because each claimant can be served exactly without any competition among claimants.

Moreover, to prevent either claimant from beating the other by claiming an infinite amount, the claims are truncated (Bergantiños and Méndez-Naya 2001, p. 225; Moulin 2003, p. 37-38, 262), that is, replaced by $E$ when $d_{i}>E$ : the claims turn out to be $\tilde{d}_{i}=\min \left(d_{i}, E\right)$ for any $i$. The truncated claims are ordered such that $\tilde{d}_{1} \leq \tilde{d}_{2} \leq \ldots \leq \tilde{d}_{n}$ with $\tilde{d}_{n} \leq E$. Obviously, $E \leq \tilde{d}$. In what follows, we omit the tilde to alleviate the notations.

As explained by O'Neill (1982), when $d_{n}=E$, the procedure runs as follows. At step 1, each of the $n$ claimants receives $\frac{d_{1}}{n}$; the procedure stops for claimant 1. At step 2, if $d_{1}=E$, the procedure stops for good. Otherwise, if $d_{1}<E$, each claimant receives $\frac{d_{1}}{n}+\frac{d_{2}-d_{1}}{n-1}$ and the procedure stops for claimant 2 who departs. And so on. This continues until step $n$ where $d_{n}=E$. A generic claimant $i$ receives (after positing $d_{0} \equiv 0$ ):

$$
x_{i}=\sum_{j=1}^{i} \frac{d_{j}-d_{j-1}}{n-j+1} \text { for any } i=1, \ldots, n
$$

We observe that

$$
x_{i}=x_{i-1}+\frac{d_{i}-d_{i-1}}{n-i+1} \text { for any } i=2, \ldots, n
$$

Table 1 shows that the total distributed at the end of any step $i$ is equal to the total of the previous step $i-1$ plus what is distributed at step $i$. Overall, only $d_{n}$ is distributed in all steps. This is not a problem here as $d_{n}=E$ and the whole estate is distributed. When $d_{n}>E, d_{n}$ is truncated and replaced by $E$ and we retrieve the preceding case. 


\begin{tabular}{|c|c|c|c|c|c|c|c|}
\hline & \multicolumn{7}{|c|}{ Step $j$} \\
\hline Claimant $i$ & 1 & 2 & 3 & 4 & $\ldots$ & $n$ & $x_{i}$ \\
\hline 1 & $\frac{d_{1}}{n}$ & & & $\ldots$ & $\ldots$ & & $\frac{d_{1}}{n}$ \\
\hline 2 & $\frac{d_{1}}{n}$ & $\frac{d_{2}-d_{1}}{n-1}$ & & $\ldots$ & $\ldots$ & & $x_{1}+\frac{d_{2}-d_{1}}{n-1}$ \\
\hline 3 & $\frac{d_{1}}{n}$ & $\frac{d_{2}-d_{1}}{n-1}$ & $\frac{d_{3}-d_{2}}{n-2}$ & $\ldots$ & $\ldots$ & & $x_{2}+\frac{d_{3}-d_{2}}{n-2}$ \\
\hline 4 & $\frac{d_{1}}{n}$ & $\frac{d_{2}-d_{1}}{n-1}$ & $\frac{d_{3}-d_{2}}{n-2}$ & $\frac{d_{4}-d_{3}}{n-3}$ & $\ldots$ & & $x_{3}+\frac{d_{4}-\bar{d}_{3}}{n-3}$ \\
\hline$\ldots$ & $\ldots$ & $\ldots$ & $\ldots$ & $\ldots$ & $\ldots$ & $\ldots$ & $\ldots$ \\
\hline$n$ & $\frac{d_{1}}{n}$ & $\frac{d_{2}-d_{1}}{n-1}$ & $\frac{d_{3}-d_{2}}{n-2}$ & $\frac{d_{4}-d_{3}}{n-3}$ & $\cdots$ & $d_{n}-d_{n-1}$ & $\begin{array}{c}x_{n-1}+ \\
d_{n}-d_{n-1}\end{array}$ \\
\hline $\begin{array}{c}\text { Total } \\
\text { distributed } \\
\text { during step } \\
j \\
\end{array}$ & $d_{1}$ & $d_{2}-d_{1}$ & $d_{3}-d_{2}$ & $d_{4}-d_{3}$ & $\cdots$ & $d_{n}-d_{n-1}$ & \\
\hline $\begin{array}{c}\text { Total } \\
\text { distributed } \\
\text { in all steps } \\
\text { up to } j \\
\end{array}$ & $d_{1}$ & $d_{2}$ & $d_{3}$ & $d_{4}$ & $\ldots$ & $d_{n}$ & $d_{n}$ \\
\hline
\end{tabular}

Table 1: Ibn Ezra procedure (case where $d_{n}=E$ )

The difficulty arises when the greatest claim is smaller than the estate (Chun and Thomson 2005; Alcalde et al. 2008). The problem is to decide how we allocate the unallocated surplus $E-d_{n}$. A greatest claim smaller than the estate, i.e., $d_{n}<E$, should be a possibility, even if it is ignored by ibn Ezra in the historical rights arbitration problem.

\section{Alcalde et al.'s Generalized ibn Ezra Value}

When $d_{n}<E$, Alcalde et al.'s (2005) Generalized ibn Ezra Value is based on the following principle: at each iteration $t$, the ibn Ezra procedure is applied, that is, each claimant $i$ receives what claimant $i-1$ has already received, plus

$$
\left(d_{i}^{t}-d_{i-1}^{t}\right) /(n-i+1)
$$

following Table 1. Obviously, at iteration 1, the demands are $d_{i}^{(1)}=d_{i}$ for any $i$ and claimant 1 receives $d_{1} / n$. If there is anything left to distribute out of the estate, the same process is repeated in a new iteration except the demand of each claimant $i$ is reduced by what has already been distributed to $i: d_{i}^{(t+1)}=$ $d_{i}^{(t)}-x_{i}^{(t)}$. Alcalde et al. (2005) provide the following example:

Example 1. Let $N=\{1,2,3\}, \mathbf{d}=(18,22,24), d=64$ and $E=41$. At iteration 1, by applying ibn Ezra's procedure we obtain:

$\mathbf{x}^{(1)}=\left(\frac{18}{3}=6,6+\frac{22-18}{2}=8,8+\frac{24-22}{1}=10\right)$ with $x^{(1)}=24$; thus, $d_{1}^{(2)}=$ $18-6=12, d_{2}^{(2)}=28-8=14, d_{3}^{(2)}=24-10=14, d^{(2)}=40$, and the residual 
estate is $E^{(2)}=41-24=17$.

At iteration 2, by applying ibn Ezra's procedure again we obtain:

$\mathbf{x}^{(2)}=\left(\frac{12}{3}=4,4+\frac{14-12}{2}=5,5+\frac{14-14}{1}=5\right)$ with $x^{(2)}=14$; thus, $\mathbf{d}^{(3)}=$ $(8,9,9), d^{(3)}=26$, and $E^{(3)}=3$.

At iteration 3, 1 is allocated to each claimant, again by ibn Ezra's procedure, which yields the solution $\mathbf{x}=(11,14,16)$.

Therefore Alcalde et al.'s (2005) method amounts to applying ibn Ezra's procedure successively on what remains to be shared. The residual estate is never increasing. Alcalde et al. (2005, pp. 37-38) prove by a property of finite convergence that the procedure converges:

Proposition 1. The Generalized ibn Ezra Value converges: $\exists T \in \mathbb{N} / E^{(T)}=0$ (Alcalde et al.'s (2005, p. 18).

Proof. The proof is in Alcalde et al. (2005, pp. 37-38).

The procedure satisfies axioms 1 and 2 .

\section{Convergence: Numerical approach}

Alcalde et al.'s (2005) Generalized ibn Ezra Value is clearly attractive. However, even if convergence of the procedure is guaranteed, it could be very slow computationally as we allocate to the total only $\max _{i} d_{i}^{(t)}$ at each iteration $t$ because the total distributed by ibn Ezra's procedure is $\sum_{i=1}^{n} x_{i}=d_{n}$ when $d_{n}<E$, as seen before.

Example 2. Consider the following example: $\mathbf{d}=(4,7,9,10), d=30$ and $E=26$. We apply Alcalde et al.'s (2005) Generalized ibn Ezra Value. Six iterations will be necessary.

At iteration $1, \mathbf{x}^{(1)}=\left(\frac{4}{4}=1,1+\frac{7-4}{3}=2,2+\frac{9-7}{2}=3,3+\frac{4-3}{1}=4\right)$ with $x^{(1)}=$ 10 ; thus, $\mathbf{d}^{(2)}=(3,5,6,6), d^{(2)}=20$, and $E^{(2)}=26-10=16$.

At iteration $2, \mathbf{x}^{(2)}=\left(\frac{3}{4}, \frac{3}{4}+\frac{5-3}{3}=1 \frac{5}{12}, 1 \frac{5}{12}+\frac{6-5}{2}=1 \frac{11}{12}, 1 \frac{11}{12}+\frac{6-6}{1}=1 \frac{11}{12}\right)$ with $x^{(2)}=6$; thus, $\mathbf{d}^{(3)}=\left(2 \frac{1}{4}, 3 \frac{7}{12}, 4 \frac{1}{12}, 4 \frac{1}{12}\right), d^{(3)}=14$, and $E^{(3)}=16-6=$ 10 .

At iteration $3, \mathbf{x}^{(3)}=\left(\frac{9}{16}, 1 \frac{1}{144}, 1 \frac{37}{144}, 1 \frac{37}{144}\right)$ with $x^{(3)}=4 \frac{1}{12}$;

thus, $\mathbf{d}^{(4)}=\left(1 \frac{11}{16}, 2 \frac{83}{144}, 2 \frac{119}{144}, 2 \frac{119}{144}\right), d^{(4)}=9 \frac{11}{12}$, and $E^{(4)}=10-4 \frac{1}{12}=5 \frac{11}{12}$.

At iteration $4, \mathbf{x}^{(4)}=\left(\frac{27}{64}, \frac{660}{919}, \frac{500}{593}, \frac{500}{593}\right)$ with $x^{(4)}=2 \frac{119}{144}$;

thus, $\mathbf{d}^{(5)}=\left(1 \frac{17}{64}, 1 \frac{684}{797}, 1 \frac{703}{715}, 1 \frac{703}{715}\right), d^{(5)}=7 \frac{13}{144}$, and $E^{(5)}=5 \frac{11}{12}-2 \frac{119}{144}=3 \frac{13}{144}$.

At iteration $5, \mathbf{x}^{(5)}=\left(\frac{81}{256}, \frac{295}{574}, \frac{411}{713}, \frac{411}{713}\right)$ with $x^{(5)}=1 \frac{703}{715}$;

thus, $\mathbf{d}^{(6)}=\left(\frac{243}{256}, 1 \frac{304}{883}, 1 \frac{24}{59}, 1 \frac{24}{59}\right), d^{(6)}=5 \frac{87}{439}$, and $E^{(6)}=3 \frac{13}{144}-1 \frac{703}{715}=1 \frac{47}{439}$. At iteration $6, \mathbf{x}^{(6)}=\left(\frac{14}{59}, \frac{69}{238}, \frac{69}{238}, \frac{69}{238}\right)$ with $x^{(6)}=1 \frac{47}{439}$;

thus, $\mathbf{d}^{(7)}=(0,0,0,0), d^{7}=0$, and $E^{(7)}=1 \frac{47}{439}-1 \frac{47}{439}=0$.

The solution is $\mathbf{x}=\left(\frac{3104}{361}, \frac{5748}{791} \frac{7529}{599}, \frac{8529}{599}\right) \sim(3.29,5.95,7.89,8.89)$ with $x=26$. 
So, depending on the value of $E$, the claims being unchanged, we may explore the change in the number of iterations that are necessary for convergence. ${ }^{5}$ The results are depicted in Figure 1. This figure shows that the method tends to converge in a growing number of iterations when $E \rightarrow d$. We may even suspect that the number of iterations tends toward infinity when $E$ approaches $d$. Paradoxically, it is when we approach the point where allocating turns out to be trivial, i.e. $E=d$, that "the ground gives way under our feet". ${ }^{6}$ This shows that the procedure may not be computationally efficient and convergence may be very slow as the procedure may require an infinite number of steps when we approach the point where the division problem turns out to be trivial. This questions the convergence of the Generalized ibn Ezra Value as stated by proposition 1. However, this intuition should be proved. This is why in what follows we illustrate it by an extended numerical example, then by an extensive numerical analysis based on Monte-Carlo experiments, and finally by a formal demonstration.

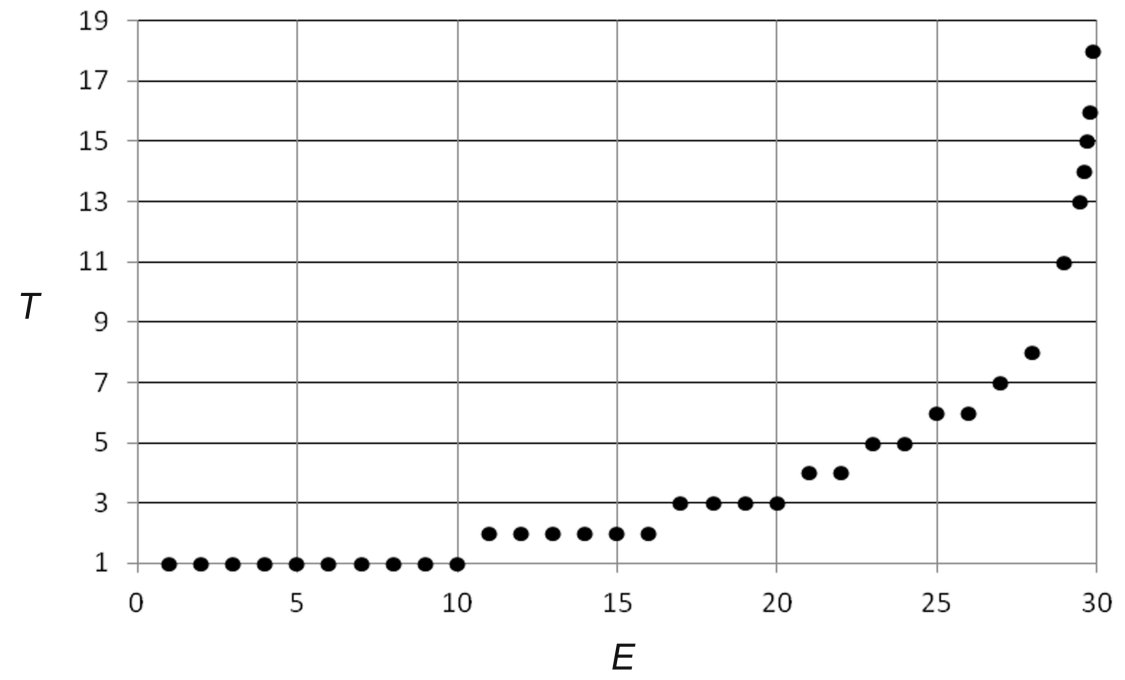

Figure 1: Alcalde et al.'s (2005) generalization: number of iterations to reach convergence, depending on $E$ with the data of Example $2 \mathbf{d}=(4,7,9,10)$, and $d=30)$.

\footnotetext{
${ }^{5}$ Obviously, when $E=d_{n}=10$, we have ibn Ezra's original case: the method converges in one iteration.

${ }^{6}$ When $E=d$ any allocation problems turn out to be trivial: they turn into a simple division, with each claimant receiving exactly what he claims, that is, $x_{i}=d_{i}$ for any $i$ because each claimant can be served exactly without any competition among claimants.
} 


\subsection{Extension of Alcalde et al.'s example}

For the extended example and the Monte-Carlo experiments, we have written a program in Maple programming language. ${ }^{7}$ It is launched by calling the procedure GiEV10 shown in appendix 6. For example,

$$
\text { GiEV 10(1000, 0, 0, 0, 0, 0, 0, 4, 7, 9, 10,26) }
$$

launches the program for a maximum of 1000 iterations, the vector of claims $\mathbf{d}=(4,7,9,10)^{8}$ and an estate of 26 (the data of example 2 ). The precision is 20 digits. The stop condition is double: either the residual estate $E^{(t)}$ is zero at iteration $t$, or, to avoid an infinite loop, the residual estate turns out to be constant, i.e., $E^{(t)}=E^{(t-1)}$, on the understanding that $E^{(t)}$ cannot be growing by construction, i.e., $E^{(t)} \leq E^{(t-1)}$. We have explored some extended examples ranging from four (the example 2) to 10 claimants. Table 2 indicates the claims of each claimant (in row) for each example. For example, column 6 corresponds to an example where $\mathbf{d}=(4,7,9,10,15,16)$.

\begin{tabular}{|c|c|c|c|c|c|c|c|c|}
\hline & \multicolumn{7}{|c|}{ vectord depending on the number of claimants } \\
\hline & & 4 & $\mathbf{5}$ & 6 & 7 & 8 & $\mathbf{9 9}$ & $\mathbf{1 0}$ \\
\hline \multirow{10}{*}{ Claimant } & 1 & 4 & 4 & 4 & 4 & 4 & 4 & 4 \\
\hline & 2 & 7 & 7 & 7 & 7 & 7 & 7 & 7 \\
\hline & 3 & 9 & 9 & 9 & 9 & 9 & 9 & 9 \\
\hline & 4 & 10 & 10 & 10 & 10 & 10 & 10 & 10 \\
\hline & 5 & & 15 & 15 & 15 & 15 & 15 & 15 \\
\hline & 6 & & & 16 & 16 & 16 & 16 & 16 \\
\hline & 7 & & & & 21 & 21 & 21 & 21 \\
\hline & 8 & & & & & 29 & 29 & 29 \\
\hline & 9 & & & & & & 30 & 30 \\
\hline & 10 & & & & & & & 34 \\
\hline \multicolumn{2}{|c|}{ Total claim } & 30 & 45 & 61 & 82 & 111 & 141 & 175 \\
\hline
\end{tabular}

Table 2: The seven examples with a growing number of claimants: Claims

For each of the seven examples, Table 3 gives the number of iterations $T$ that are necessary to solve the bankruptcy problem when $E \rightarrow d$. The table should be read as follows: the example of six claimants and $E=61-10^{-2}=60.99$ requires 44 iterations to be solved. We deduce two findings of Table 3:

1. More claimants (when we read Table 3 from the left to the right) requires more iterations to solve the problem. Considering a very large number of claimants, as the whole population of a country, would "explode" the number of iterations. This could be expected because the loop for $n$ in

\footnotetext{
${ }^{7}$ Exactly, Maple 18.02. Maple is a popular mathematical software scientific computing software.

${ }^{8}$ The procedure is able to handle up to 10 claimants. For four claimants, we set the first six claims to zero.
} 
procedure GiEV10 becomes longer (i.e., we have more steps), $n$ being multiplied by $T$.

2. When $E$ grows to approach $d$ (i.e., when we read Table 3 from the top to the bottom) we need more iterations. This result was somewhat expected because the two first columns correspond to what is depicted by Figure 1. 


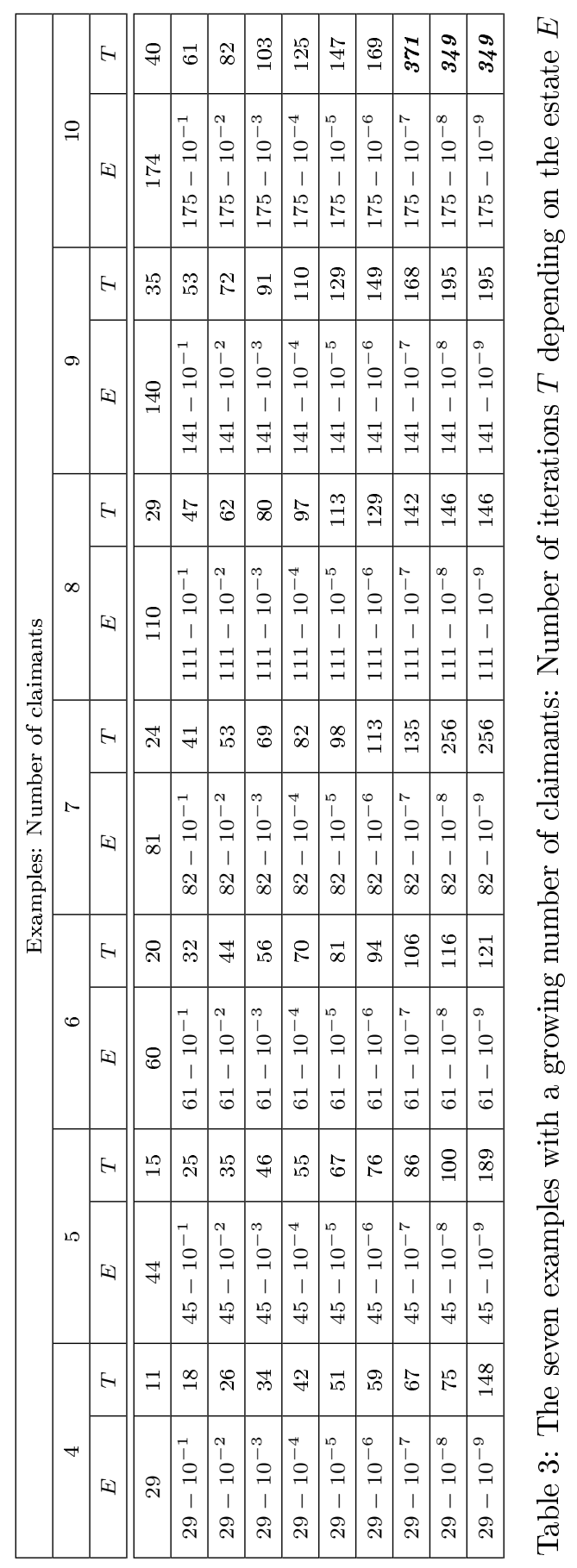


However, such examples may be considered as particular and arbitrary. This is why we now conduct some Monte-Carlo-like experiments to confirm or infirm the intuition of the seven examples of Table 2.

\subsection{Monte-Carlo experiments}

We consider the gap between $E$ and $d$, so that the gap is independent of the magnitude of $E$ and $d$. To do this, we conduct the experiments such that the relative gap between $d$ and $E$ decreases exponentially in base 10, that is,

$$
\frac{d-E}{d}=10^{-g}
$$

i.e., $E=\left(1-10^{-g}\right) d$ (we take $g$ integer): the parameter $g$ is the exponent of the relative gap between $d$ and $E: \frac{d-E}{d}=10^{-g}$. We adapt the procedure $G i E V 10$ so that it turns out to be a subroutine GiEVr, which is called by a new procedure, GiEVMC the arguments of which are: $N$ the maximum number of claimants, $G$ the maximum value for $g$, and $M C$ the number of times that we compute each solution of a Generalized ibn Ezra Value problem, with the claims being randomly chosen. The program GiEVMC and the subroutine GiEVr are provided in appendix 6. In $G i E V r$ we have an instruction " $E=d s(1-g a p)$ :", where $d s$ is for the variable $d$, and gap is for $10^{-g}$, as transmitted by the procedure GiEVMC. To produce the vector $\mathbf{d}$, the demand of claimant $i$ is deduced from the demand of claimant $i-1$ by adding a number randomly chosen between 0 and 10 as done by the instruction " $d[i]:=d[i-1]+r():$ :. Each problem converges in $T$ iterations, a number transmitted by the subroutine $G i E V r$ to the program GiEVMC ( $T$ is set "global" by the instruction "global $T$ :"). The subroutine $G i E V r$ is repeated $M C$ times and we calculate the average number of iterations necessary to reach convergence.

For example, GiEVMC(40,9,100) computes the average number of iterations that are necessary to converge for 100 experiments, conducted for a number of claimants ranging from two to 40 and for $g=1 \Rightarrow \frac{d-E}{d}=10 \%$ up to $g=9 \Rightarrow \frac{d-E}{d}=10^{-9}$. The results of $\operatorname{GiEVMC}(40,9,100)$ are given in Table 4. All told, $39 \times 9 \times 100=35100$ ibn Ezra problems are solved by calling up the GiEVr subroutine each time. As this represents a lot of computing time, we do not go further. Obviously, the average number of iterations is fractional even if the numbers of iterations are themselves integers. 


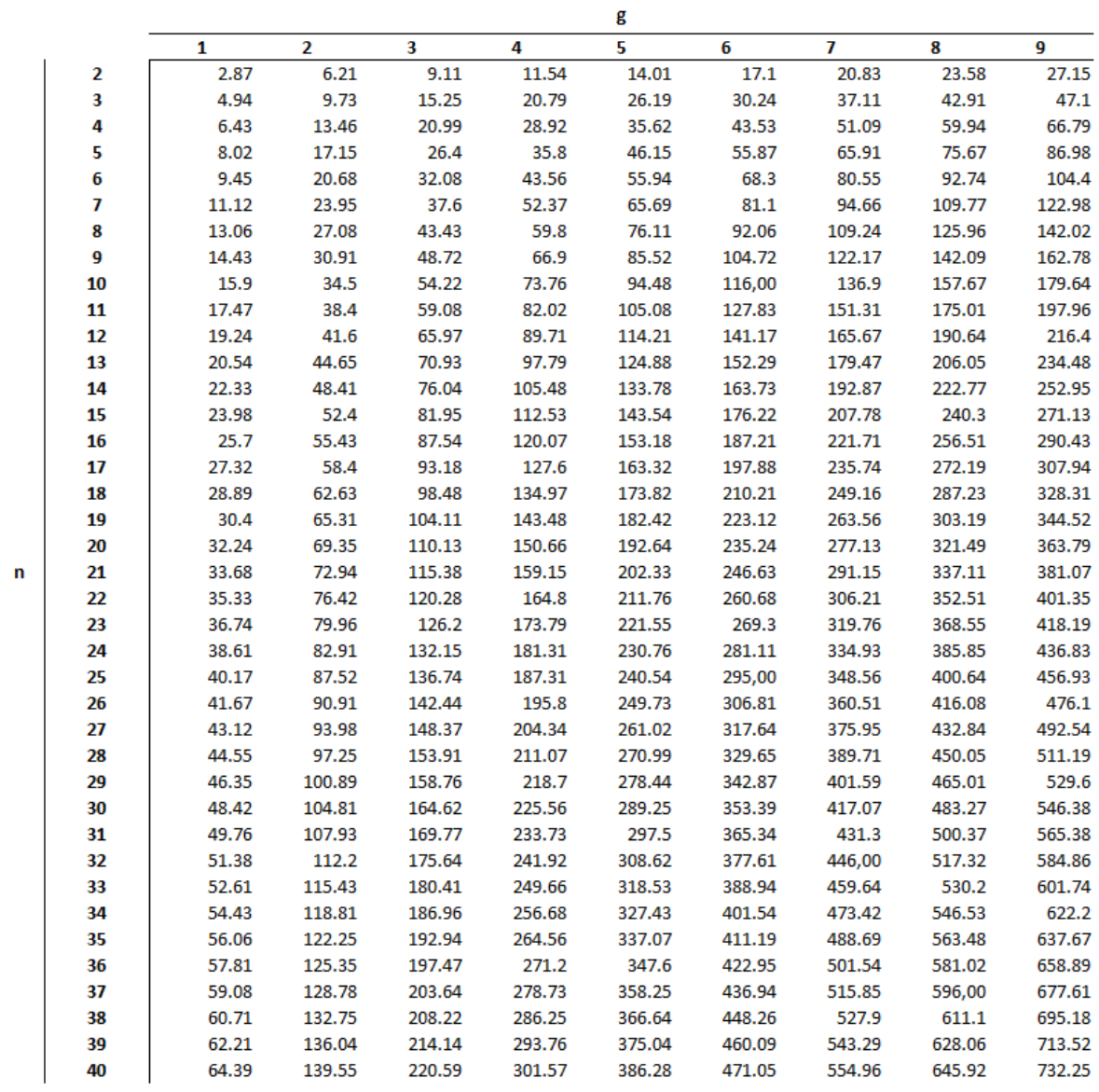

Table 4: Monte-Carlo experiments: Number of iterations $T$ depending on $g$ such that $\frac{d-E}{d}=10^{-g}$ and on the number of claimants $n$, for $g=\{1 \ldots 9\}$ and $n=\{2 \ldots 40\}$ claimants.

These experiments confirm the intuition of the two findings of the seven examples of Table 2 and Table 3 above. This is formalized in two dual empirical results 1 and 2 below.

Empirical result 1. In the Generalized ibn Ezra Value, when the gap between $E$ and $d$ is measured in relative terms, for a given value of $g=\lg _{10}\left(\frac{d-E}{d}\right)$, the number of iterations linearly grows with the number of claimants $n$.

To obtain this empirical result, we study the linear regressions

$$
T=a n-b
$$

The coefficients that best fit the data of Table 4 are given in Table 5. The 
correlation coefficient is very good: $R^{2} \geq .9999$. With the help of Table 5 we are able to forecast the results for more claimants by performing a linear regression on the coefficients $a$ and $b$. We obtain

$$
a=2.1164 g-.739 \text { with } R^{2}=.9995
$$

and

$$
b=.7249 g-1.0024 \text { with } R^{2}=.9809
$$

For example, when $g=9$, we may expect that $a=18.3036$ from (3) and $b=5.5217$ from (4), so that (2) turns out to be

$$
T=18.3036 n-5.5217
$$

which gives $T=1825$ for $n=100$. When $g=2$ (i.e., a reasonable relative difference between $E$ and $d$ of $1 \%$ ), (5) indicates that we should have roughly 3.5 billion iterations for 1 billion claimants (billion is a realistic number for a real bankruptcy).

\begin{tabular}{|c||c|c|c|}
\hline \multicolumn{1}{|c||}{$g$} & \multicolumn{2}{c|}{$T=a n-b$} & \multirow{2}{*}{$R^{2}$} \\
\cline { 2 - 3 } & $a$ & $b$ & \\
\hline \hline 1 & 1.603 & .0371 & .9999 \\
\hline 2 & 3.5071 & .6518 & .9999 \\
\hline 3 & 5.5262 & 1.0797 & .9999 \\
\hline 4 & 7.5914 & 1.5307 & .9999 \\
\hline 5 & 9.7206 & 2.442 & .9999 \\
\hline 6 & 11.888 & 3.2273 & .9999 \\
\hline 7 & 14.039 & 3.7605 & 1 \\
\hline 8 & 16.252 & 4.9372 & 1 \\
\hline 9 & 18.46 & 5.9317 & 1 \\
\hline
\end{tabular}

Table 5: Monte-Carlo experiments: $T=a g-b$ depending on $n$

Empirical result 2. In the Generalized ibn Ezra Value, when the gap between $E$ and $d$ is measured in relative terms, for a given value $n$ of the number of claimants, the number of iterations linearly grows with respect to $g=$ $\lg _{10}\left(\frac{d-E}{d}\right)$. This result means that the number of iterations linearly grows each time the gap is divided by 10, which is consistent with Figure 1.

To obtain this result, we study the linear regressions

$$
T=a g-b
$$

The coefficients that best fit the data of Table 4 are given in Table 6 . The correlation coefficient is very good: $R^{2} \geq .9972$. Again, with the help of Table 6 
we are able to forecast the results for a larger number of claimants by performing a linear regression on the coefficients $a$ and $b$. We obtain

$$
a=2.1164 n-.7248 \text { with } R^{2}=1
$$

and

$$
b=.7386 n-1.0367 \text { with } R^{2}=.9983
$$

For example, when $n=100$, we may expect that $a=210.915$ from (7) and $b=72.823$ from (8), which implies that 6 turns out to be

$$
T=210.915 g-72.823
$$

and we have $T=1825$ for $g=9$ : we retrieve the result obtained for the projection of empirical result 1 , by duality. 


\begin{tabular}{|c||c|c|c|}
\hline \multirow{2}{*}{$n$} & \multicolumn{2}{|c|}{$T=a g-b$} & \multirow{2}{*}{$R^{2}$} \\
\cline { 2 - 3 } & $a$ & $b$ & \\
\hline \hline 2 & 2.9705 & .1414 & .9972 \\
\hline 3 & 5.3558 & .7503 & .9886 \\
\hline 4 & 7.5948 & 1.664 & .9995 \\
\hline 5 & 9.8415 & 2.7686 & .9994 \\
\hline 6 & 11.961 & 3.3939 & .9997 \\
\hline 7 & 14.129 & 4.0636 & .9997 \\
\hline 8 & 16.273 & 4.8344 & .9997 \\
\hline 9 & 18.528 & 6.1672 & .9993 \\
\hline 10 & 20.535 & 6.7758 & .9995 \\
\hline 11 & 22.701 & 7.4872 & .9996 \\
\hline 12 & 24.777 & 7.8172 & .9996 \\
\hline 13 & 26.859 & 8.6194 & .9998 \\
\hline 14 & 28.958 & 9.4158 & .9997 \\
\hline 15 & 31.128 & 10.101 & .9996 \\
\hline 16 & 33.294 & 11.161 & .9996 \\
\hline 17 & 35.321 & 11.763 & .9996 \\
\hline 18 & 37.468 & 12.484 & .9995 \\
\hline 19 & 39.478 & 12.932 & .9997 \\
\hline 20 & 41.687 & 13.692 & .9996 \\
\hline 21 & 43.685 & 14.042 & .9997 \\
\hline 22 & 46.002 & 14.042 & .9995 \\
\hline 23 & 47.903 & 15.734 & .9997 \\
\hline 24 & 50.118 & 16.759 & .9996 \\
\hline 25 & 52.296 & 17.765 & .9995 \\
\hline 26 & 54.34 & 18.359 & .9995 \\
\hline 27 & 56.379 & 18.582 & .9997 \\
\hline 28 & 58.586 & 19.776 & .9996 \\
\hline 29 & 60.587 & 20.465 & .9995 \\
\hline 30 & 62.666 & 20.799 & .9996 \\
\hline 31 & 64.908 & 22.197 & .9995 \\
\hline 32 & 67.095 & 22.635 & .9996 \\
\hline 33 & 68.976 & 22.974 & .9997 \\
\hline 34 & 71.2 & 24.002 & .9996 \\
\hline 35 & 73.138 & 24.143 & .9996 \\
\hline 36 & 75.52 & 26.065 & .9995 \\
\hline 37 & 77.64 & 26.547 & .9996 \\
\hline 38 & 79.572 & 27.079 & .9996 \\
\hline 39 & 81.766 & 28.144 & .9995 \\
\hline 40 & 83.813 & 28.335 & .9995 \\
\hline & & & \\
\hline
\end{tabular}

Table 6: Monte-Carlo experiments: coefficients $a$ and $b$ of $T=a g-b$ depending on $n$ 


\section{Convergence when $E$ tends to $d$ : Theoretical approach}

A first intuition about the difficulties of convergence of the algorithm of Alcalde et al.'s (2005) is simple. Following Table 1, ibn Ezra's procedure allocates at each iteration $t$ only $d_{n}^{(t)}$ to the total. As the Generalized ibn Ezra Value applies ibn Ezra's procedure at each iteration, it allocates a relatively minor part of the estate each time, which leads to a tardy algorithm. We will demonstrate this rigorously now. Remember that, in mathematical wording, the algorithm converges at iteration $t$ if the residual estate $E^{(t+1)}$ is equal to zero. We begin by a simple example where $E=d$.

Example 3. We return to example $2(\mathbf{d}=(4,7,9,10), d=30)$ but we posit $E=d$, that is, $E=30$.

At iteration $1, \mathbf{x}^{(1)}=\left(\frac{4}{4}=1,1+\frac{7-4}{3}=2,2+\frac{9-7}{2}=3,3+\frac{4-3}{1}=4\right)$ with $x^{(1)}=$ 10 ; thus, $\mathbf{d}^{(2)}=(3,5,6,6), d^{(2)}=20$, and $E^{(2)}=30-10=20$. We observe that $d^{(2)}=E^{(2)}$.

At iteration $2, \mathbf{x}^{(2)}=\left(\frac{3}{4}, \frac{3}{4}+\frac{5-3}{3}=1 \frac{5}{12}, 1 \frac{5}{12}+\frac{6-5}{2}=1 \frac{11}{12}, 1 \frac{11}{12}+\frac{6-6}{1}=1 \frac{11}{12}\right)$ with $x^{(2)}=6$; thus, $\mathbf{d}^{(3)}=\left(2 \frac{1}{4}, 3 \frac{7}{12}, 4 \frac{1}{12}, 4 \frac{1}{12}\right), d^{(3)}=14$, and $E^{3}=20-6=14$. Again $d^{(3)}=E^{(3)}$.

At iteration $3, \mathbf{x}^{(3)}=\left(\frac{9}{16}, 1 \frac{1}{99}, 1 \frac{19}{74}, 1 \frac{19}{74}\right)$ with $x^{(3)}=4 \frac{1}{12}$;

thus, $\mathbf{d}^{(4)}=\left(1 \frac{11}{16}, 2 \frac{49}{85}, 2 \frac{81}{98}, 2 \frac{81}{9}\right), d^{(4)}=9 \frac{11}{12}$, and $E^{(4)}=14-4 \frac{1}{12}=9 \frac{11}{12}$ and again $d^{(4)}=E^{(4)}$.

And so on to infinity, while the result should be immediate: the trivial allocation is obviously $\mathbf{x}=(4,7,9,10)$ with $x=30$.

Lemma 1. In the Generalized ibn Ezra Value, any iteration $t$ for which $E^{(t)}=$ $d^{(t)}$ does not reach the solution (i.e., $x^{(t)}=d^{(t)}$, that is, $E^{(t+1)}=0$ ).

Proof. Consider an iteration $t$ for which $E^{(t)}=d^{(t)}$. By ibn Ezra principle, only $x^{(t)}=d_{n}^{(t)}<d^{(t)}$ is distributed at iteration $t$. There remains $E^{(t+1)}=$ $E^{(t)}-d_{n}^{(t)}>0$ to be distributed.

Remark. Obviously, when $E<d$, there is an iteration $t=T$ for which we have $x^{(T)}=d^{(T)}$, that is, $d_{n}^{(t)}=d^{(t)}$, which implies $E^{(T+1)}=0$ : the algorithm converges (in six iterations in example 2), but it does so slowly as expounded in section 4 .

Lemma 2. In the Generalized ibn Ezra Value, when $E=d$, it holds that $E^{(t)}=$ $d^{(t)}$ for every iterations.

When $E=d$, as $E^{(t)}=d^{(t)}>0$ for any $t$, the situation of iteration 1 is perpetuated indefinitely.

Proof. We will prove Lemma 2 by recurrence. We have by hypothesis $n$ claimants and $E=d$, which implies $E-d_{n}=d-d_{n}>0$. At the first iteration the algorithm delivers $x^{(1)}=d_{n}^{(1)} \equiv d_{n}$ to the whole set of claimants; the residual 
demand is $d^{(1)}=d-d_{n}>0$ and a residual estate of $E^{(1)}=E-x^{(1)}=d-d_{n}=$ $d^{(1)}>0$ remains to be shared. Consequently, the residual estate is still equal to the residual demand. At iteration $2, x^{(2)}=d_{n}^{(2)}$ is allocated to the whole set of claimants, so the residual demand is $d^{(2)}=d^{(1)}-d_{n}^{(2)}=E^{(1)}-d_{n}^{(2)}>0$. The remainder to be shared is

$$
E^{(2)}=E^{(1)}-x^{(2)}=d^{(1)}-d_{n}^{(2)}=d^{(2)}>0
$$

The residual estate is again equal to the residual demand. Let us assume that the property is true at iteration $t$ : the quantity $x^{(t)}=d_{n}^{(t)}$ is allocated to the whole set of claimants, the residual demand is $d^{(t)}=d^{(t-1)}-d_{n}^{(t)}>0$. This leaves

$$
E^{(t)}=d^{(t)}>0
$$

to be shared and we have

$$
E^{(t)}-d_{n}^{(t+1)}>0
$$

Now, we prove that the property is true at iteration $t+1$. By the ibn Ezra procedure, the quantity $x^{(t+1)}=d_{n}^{(t+1)}$ is allocated to the whole set of claimants. So the residual demand is $d^{(t+1)}=d^{(t)}-d_{n}^{(t+1)}=E^{(t)}-d_{n}^{(t+1)}>0$ by (9) and (10). There remains to be shared

$$
E^{(t+1)}=E^{(t)}-x^{(t+1)}=d^{(t)}-d_{n}^{(t+1)}=d^{(t+1)}>0
$$

The residual estate $E^{(t+1)}$ is still equal to the residual demand $d^{(t+1)}$.

Lemma 3. In the Generalized ibn Ezra Value when $E=d$, the residual estate $E^{(t)}$ is always decreasing for any $t$.

Proof. From (11), $E^{(t)}<E^{(t-1)}$ for any $t$.

Theorem 1. In the Generalized ibn Ezra Value, when $E=d$, Alcalde et al.'s (2005) algorithm does not converge in a finite number of iterations.

Proof. Lemma 2 shows that all iterations are of the type $E^{(t)}=d^{(t)}$ and Lemma 1 shows that these iterations do not reach the solution. Combining them, we deduce that no iteration is able to reach the solution. As Lemma 3 indicates that the residual estate is always decreasing, the algorithm runs infinitely, $E^{(t)}$ asymptotically tending to zero.

Theorem 1 means that $T$ is infinite when $E=d$. It expounds a particularly annoying problem if we consider the case $E=d$ : the procedure should yield the exact solution because the bankruptcy problem turns out to be trivial, and, as the algorithm fails to reach the solution in a finite number of iterations when $E=d$ following Theorem 1, there is a clear flaw in Alcalde et al.'s (2005) Generalized ibn Ezra Value.

Remark. In mathematical terms, the function $E \in \mathbb{R}^{+} \rightarrow T_{d}(E) \in \mathbb{N}$ is not defined when $E=d . \quad d$ is an asymptote and the function $T_{d}(E)$ tends to infinity when $E$ tends to its asymptote $d .^{9}$

\footnotetext{
${ }^{9}$ To take a comparison, the function $y=\frac{1}{1-x}$ is not defined for $x=1$ and the function tends to infinity when $x \rightarrow 1$.
} 


\section{Conclusion}

We have $n$ claimants who want to share out an estate. The total of their claims $d$ is larger than the estate $E$ (otherwise, we have no problem of apportionment). When the maximum claim $d_{n}$ (that of the $n^{\text {th }}$ claimant) is equal to the estate - knowing that the claims that exceed the available estate are truncated-, O'Neill (1982) explains clearly how the solution to ibn Ezra's problem can be easily found in $n$ steps. However, when the greatest claim is for less than the estate, the question of what to do with the difference $E-d_{n}$ is posed. An attractive answer is that proposed by Alcalde et al. (2005): the Generalized ibn Ezra Value, which solves the problem in $T$ iterations, of $n$ steps; this algorithm is convergent (Alcalde et al. (2005, p. 18). However, this algorithm fails on two points:

- First, we have shown by numerical experiments that the number of iterations grows linearly with respect to the number of claimants $n$, which makes the Generalized ibn Ezra Value impracticable when the number of claimants is large, which is the case in most real applications (empirical result 1).

- Secondly, again by numerical experiments, we shown that the number of iterations linearly grows when the estate $E$ tends exponentially to the total claims $d$ : if we define by $g$ the exponent of the relative gap between $d$ and $E$ (such that $\frac{d-E}{d}=10^{-g}$, i.e., the percentage $\frac{d-E}{d}$ varies by a magnitude of 10 each time), the number of iterations grows linearly with respect to $g$ when $E$ approaches to $d$ (empirical result 2). Moreover, we have proved through theory by a fundamental theorem that the Generalized ibn Ezra Value algorithm fails to give a solution in a finite number of iterations in the trivial case $E=d$ (theorem 1), whereas it should obviously find a solution in one iteration. Overall, if we combine these two last results, even if the Generalized ibn Ezra Value is convergent, the sum of claims $d$ appears as an asymptote that can only be reached to the price of a growing number of iterations, that tends to infinite when the estate $E$ approaches the claims total $d$.

We conclude that the Generalized ibn Ezra Value algorithm is inefficient and usable only when: (i) the number of claimants is low, and (ii) the estate $E$ is largely lower than the total claims $d$. This singularly reduces its interest.

For future researches, it could be interesting to examine if it is the case for other methods, such that the O'Neil's (1982) Minimal Overlap Rule and Bergantiños and Méndez-Naya's (2001) Extended Ibn Ezra Rule, by examining their convergence properties in a similar manner. ${ }^{10}$ This is another story.

\footnotetext{
${ }^{10}$ Beyond the replication analyses conducted by Chun and Thomson (2005) on the Minimal Overlap Rule.
} 


\section{References}

ALCALDE J., MARCO M. and SILVA J. (2005) "Bankruptcy games and the Ibn Ezra's proposal," Economic Theory, 26,1: 103-114.

ALCALDE J., MARCO M. and SILVA J. (2008) "The minimal overlap rule revisited," Social Choice and Welfare, 31: 109-128.

BERGANTINOS G. and MENDEZ-NAYA L. (2001) "Additivity in bankruptcy problems and in allocation problems", Spanish Economic Review, 3, 3: 223-229.

CHUN, Y. and THOMSON W. (2005) "Convergence under replication of rules to adjudicate conflicting claims," Games and Economic Behavior, 50,2: 129-142.

Ibn EZRA A. (1146) Sefar ha-Mispar ("The Book of the Number," in Hebrew), Verona (German trans: Silberberg M. (1895), Frankfurt am Main: Kauffmann.

MOULIN H.J. (2003) Fair Division and Collective Welfare, Cambridge: MIT Press.

PEYTON YOUNG H. (1987) "On dividing an amount to individual claims or liabilities", Mathematics of Operations Research, 12, 3: 398-414.

O'NEILL B. (1982) "A problem of rights arbitration from the Talmud," Mathematical Social Sciences, 2, 4: 345-71.

RABINOVITCH N.L. (1973) Probability and Statistical Inference in medieval Jewish Literature. Toronto: University of Toronto Press.

THOMSON W. (2003) "Axiomatic and game-theoretic analysis of bankruptcy and taxation problems: a survey," Mathematical Social Sciences, 45: 249-297. 


\section{Appendix}

\section{Procedure GiEV10}

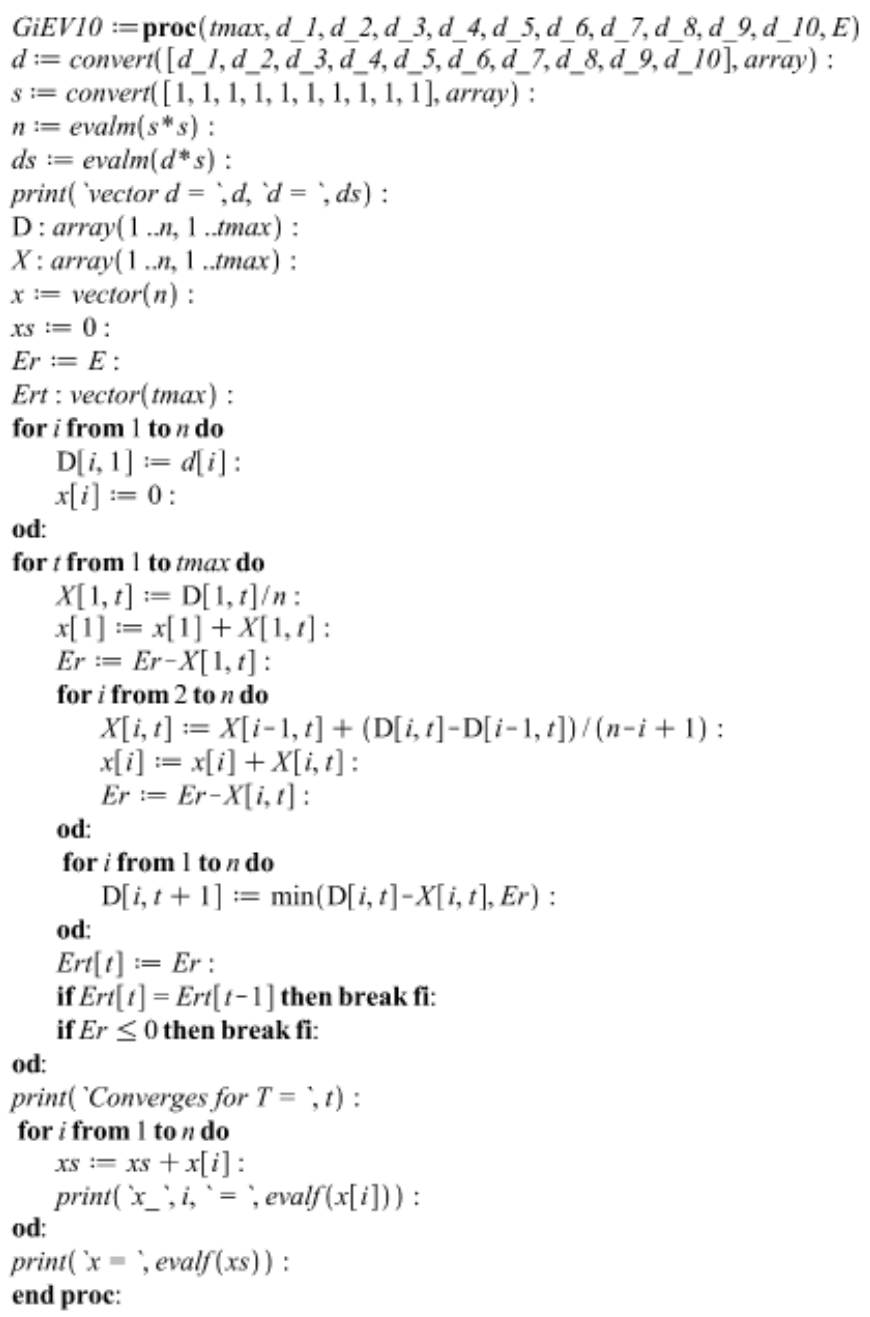

Figure 2: Procedure GiEV10 


\section{Subroutine GiEVr, procedure GiEVMC}

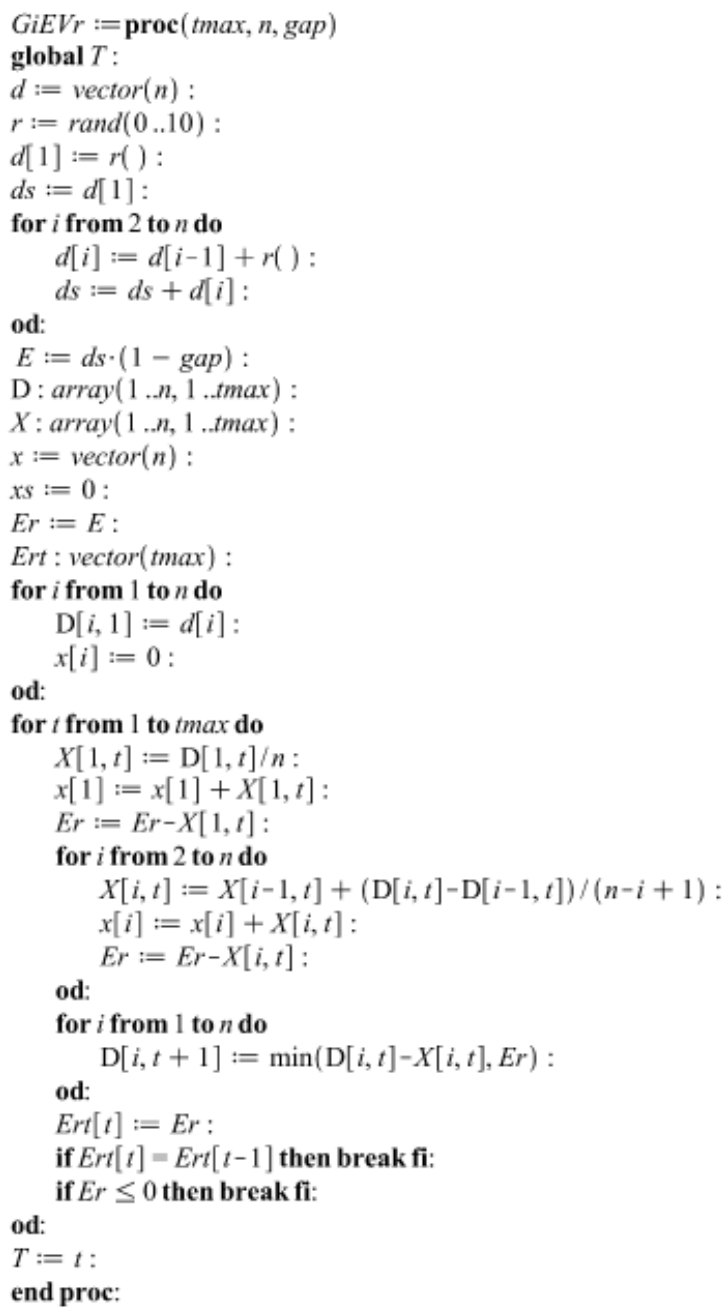

Figure 3: Subroutine GIEVr 


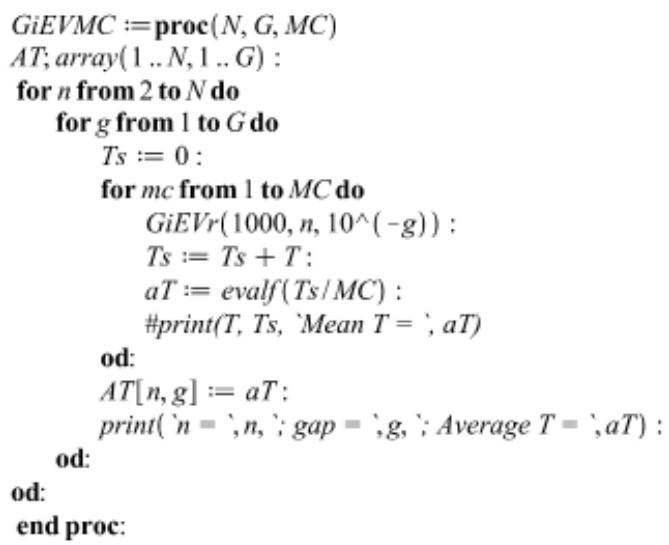

Figure 4: Procedure GIEVMC 